\title{
Chapter 6 \\ The Relationship Between Work \\ Engagement and Sustainable \\ Performance
}

\begin{abstract}
Be engaged, be happy, as the theory of engagement teaches us. To feel that you are doing exactly that where your unique talents and interests lie and where you make optimal use of personal and work-related energy sources. Who does not want to be engaged? And which manager does not desire to have engaged employees? In tough times, engagement provides extra energy to cope with stressful situations, making these employees invaluable to the organization they work in. However, studies into engagement show that almost $90 \%$ of the employees interviewed experience this work and life joy to a lesser extent, or not at all.
\end{abstract}

Keywords Work engagement theory $\cdot$ Personal resources $\cdot$ Work-related resources $\cdot$ Sustainable performance

\subsection{Introduction}

What makes someone engaged in their work and under which conditions can he or she perform optimally? And is work engagement something that can be taught and/or stimulated? Answers to these questions could help us achieve sustainable performance in our daily lives and provide us with more fun and energy in doing so. Or they could help us to avoid doing things that only lead to stress and negative energy. To what extent are vigor, dedication, and absorption (the three aspects of work engagement) required to recover that energy again, day after day?

And how important is work engagement for sustainable performance? Below is my hypothesis:

\section{Hypothesis 3}

Having work engagement to a greater or lesser degree, positively or negatively influences the relationship between talent and performance (Fig 6.1). 


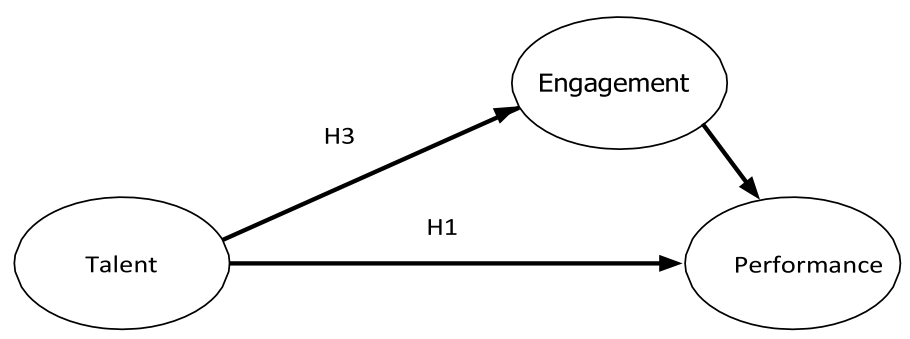

Fig. 6.1 Hypothesis 3

\subsection{Success Through Enthusiasm}

Studies on work engagement unequivocally show that each success an organization experiences originates from the enthusiasm and passion of its employees. Engaged employees work harder and are more focused (Van Rhenen 2008; Bakker et al. 2009; Kodden and Hupkes 2019; Kodden and Groenveld 2019). This is something organizations will definitely find useful in our current economic climate; achieving more with less people. Engaged employees are also very fit and confident in terms of their private lives (Bakker et al. 2009). They add a lot of value to their employers. But not just for their employers; engaged individuals are more likely to change jobs if they do not feel sufficiently challenged and/or create their own positive feedback by taking on a positive attitude and a great radius of action. Engaged individuals are capable of facing their fears and taking the necessary steps to achieve their final goal.

\subsection{The Theory of Work Engagement}

Thanks to Einstein, we know that energy forms the basis of everything. Without energy, we would not have raw materials, there could be no labor and there would not be any finished products. Energy is required to manufacture any product that you might find in a store. You also need the energy to achieve great things. The more energy, the better. You have to constantly take action. Never standstill.

The theory of work engagement (Bakker et al. 2009) posits that an engaged employee has a very positive attitude, which is characterized by boundless vitality, energy, and a will to work and invest effort. Engagement is a positive, affective-cognitive state of supreme satisfaction.

Engagement is an attitude towards life that means you try to make the most of your talents and passions using as much vigor, dedication and absorption as possible. Engage life and live happy, that is what The theory of work engagement tells us. The feeling that your activities in life perfectly match your unique talents and interests, enabling you to make the most of your energy sources, both at home and at work. Who wouldn't want to feel engaged in daily life? And what employer wouldn't 
desire engaged employees? In difficult times, work engagement can provide the extra energy required to manage stressful situations, demonstrating how valuable such employees are to their organizations. Yet, studies on work engagement show that less than $20 \%$ of surveyed employees fully experience this type of joy in their work and lives. In fact, earlier studies indicated that many professionals have lost their work engagement as a result of their talents not being recognized or the rigid structure of their organization.

\subsection{Supreme Satisfaction}

According to the theory of work engagement, the state of supreme satisfaction is characterized by vigor, dedication, and absorption. The exact meaning of these three might not be immediately evident, therefore they can be defined as follows:

- "Vigor" refers to high levels of energy, feeling fit and strong, being able to work for long periods without getting tired.

- "Dedication" is all about being strongly involved in one's work. Work is regarded as useful and meaningful, inspiring, and challenging and creates feelings of enthusiasm.

- Lastly, "Absorption" refers to being happily engrossed in one's work, resulting in one losing their sense of time and finding it difficult to detach (Bakker et al. 2009).

Engaged people are open to new ideas, are both physically and mentally healthy, look for their authentic talents, and start every day full of energy and vigor and ready to work. This is not just a positive for the person him or herself, it also stimulates their immediate coworkers and has a positive effect on the organization.

\subsection{Highly Energetic Leading Doers}

Although the definition of work engagement was and still is very clear (Bakker et al. 2009), my mind went back to the link and my affinity with sports and energy while I was helping young ambitious students transform themselves into future leaders. To me, the new heroes were Highly Energetic Responsible Operators (HERO). One night in 2013 , I created my own definition of engaged people, in part because I felt the theory of work engagement was lacking an important aspect of using one's talents. For instance, in the past, I always felt that I was engaged, but I could not always apply my energy in a useful way because I was not using my talents correctly or because I lacked direction. When I took charge of my own life, I rediscovered my talents and my energy. Only then did my performance truly start to improve. That is how I came up with the acronym HERO (Kodden 2014) (Fig. 6.2). 


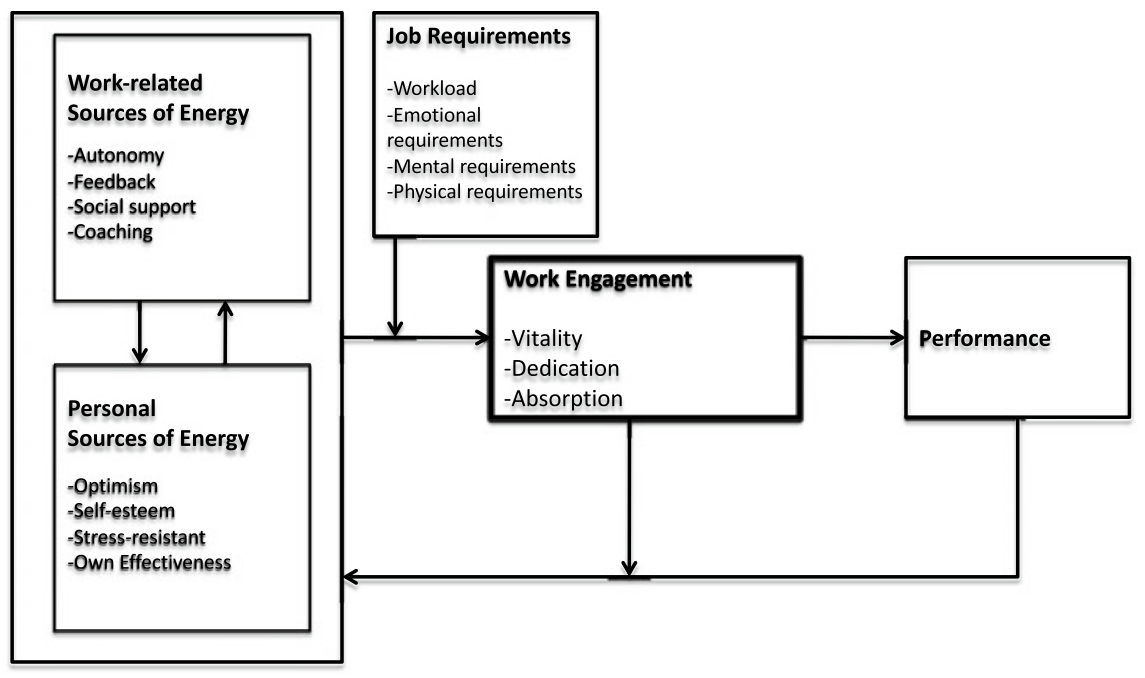

Fig. 6.2 The work engagement model (Bakker et al. 2009)

\subsection{Personal Sources of Energy}

Longitudinal studies indicate that once people are engaged, they tend to remain that way (Bakker et al. 2009; Kodden and Van Ingen 2019). This is an important conclusion to consider when striving for a positive attitude. People with multiple sources of energy (energy sources that you are personally responsible for, such as optimism, self-esteem, stress resistance, and self-efficacy) are able to better safeguard their own interests and stay intrinsically motivated for a longer time (Xanthoupoulou et al. 2008a, b). They strive to achieve goals because these fit their personal interests and ideas, rather than because other people order them around.

In 2003, Wiese, Rothmann and Storm discovered a positive correlation between personal sources of energy and work engagement in police officers. They appeared to have an active coping style. They were problem-oriented and actively took steps to reduce stress and remain engaged.

Another important discovery was made by Xanthoupoulou (2008a, b). Her team of scientists demonstrated that personal sources of energy have mutually beneficial relation to work-related sources of energy.

The more engaged employees were, the more access they got to additional workrelated sources of energy and vice versa. Sources of energy - such as increased autonomy, coaching, and team atmosphere-could be reinforced through optimism and positive energy.

The infectiousness of work engagement is not just limited to work colleagues. For example, it seems very likely that work engagement has a positive influence on the enthusiasm of others. Recent studies show that employees can even influence their partner at home through their enthusiasm (Westman et al. 2011). 
As many large-scale studies show, including my own Ph.D. work, work engagements is crucial to (knowledge) organizations. For example, a global survey by Gallup (2013) shows that work engagement has several positive effects on organizations, ensuring:

- Less absenteeism $(-37 \%)$;

- Fewer accidents $(-49 \%)$;

- Fewer quality issues $(-60 \%)$;

- Higher customer satisfaction $(+12 \%)$;

- Greater productivity $(+18 \%)$; and

- Higher profits $(+16 \%)$.

It, therefore, seems that the importance of employees' work engagement for sustainable performance should not be underestimated.

The presence of talent appears to be a prerequisite for performance, but this only explains - in complete accordance with Ericsson and Colvin's theories-a small part of the measured variety of performance levels. The level of engagement, the ability to meet the job requirements, and especially the presence of certain critical personality traits turn out to be much more important(see Appendix B: Important results of the study on performance indicators).

At this stage of my research, my curiosity about the importance of work engagement and its aspects of vigor, dedication, and absorption was as great as ever. To what degree do these elements, in addition to talent and other performance indicators, influence sustainable performance today (Fig. 6.3)?

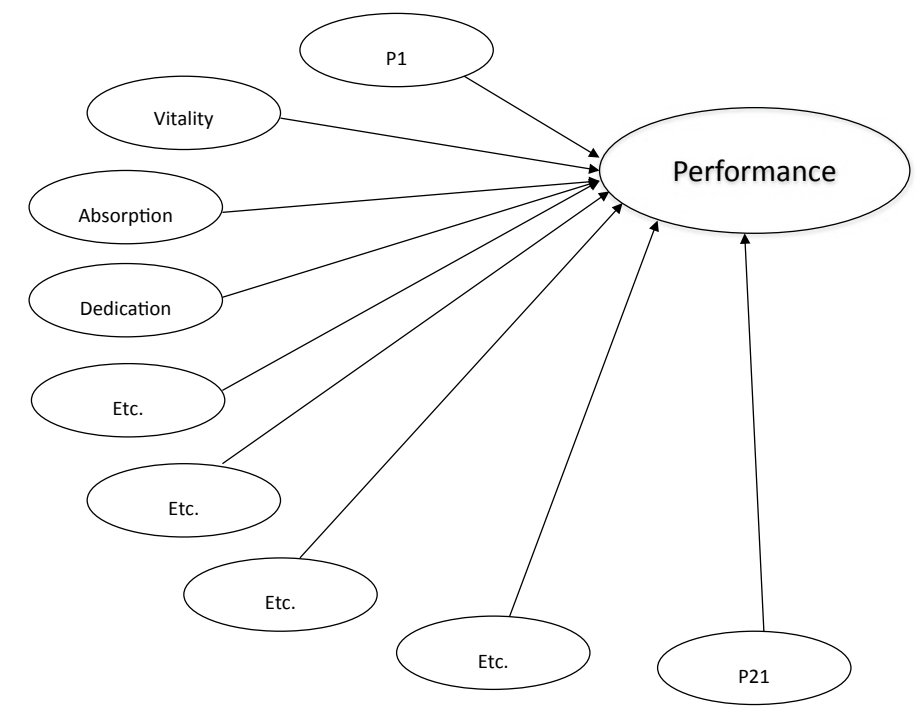

Fig. 6.3 Study on performance indicators and the three aspects of work engagement 


\subsection{Results of the Study}

This study unequivocally shows that employees' work engagement is vital to performance. Of the five variables (talent, personality traits, fit with the organization, work engagement, and job requirements), the level of engagement-following certain specific personality traits-is the most important indicator for organizations in order to achieve new results. Moreover, these specific personality traits turn out to influence the level of engagement. One and one makes three, it seems!

Engaged employees perform better, that much is clear. As this study has shown, dedication (the number 6 performance predictor) and vigor (number 7) are especially crucial for sustainable performance!

Which specific personal trait is then the most important predictor for work engagement? Intrinsic motivation! My study shows that intrinsically motivated people also have higher levels of work engagement. This is in accordance with Daniel Pink's theory (2009).

The Dutch CEOs did pay particular attention to this performance indicator and rated the elements of dedication and absorption of work engagement as number 6 and number 13, respectively, of the most important selection criteria. They do not consider the vigor of candidates as important as has been suggested by this study. Dutch CEOs place vigor at the 11th place of important selection criteria!

\section{References}

Bakker A, Schaufeli W, Van Rhenen W (2009) How changes in job demands and resources predict burnout, work engagement, and sickness absenteeism. J Organ Behav

Gallup (2013) Worldwide, 13\% of employees are engaged at work. http://www.gallup.com/poll/ 165269/worldwide-employees-engaged-work.aspx

Kodden S (2014) Be a HERO. How to bring out leadership in everyone. Bernard Daniel Press

Kodden B, Groenweg B (2019) The mediating effect of work engagement on the relationship between person-organization fit and knowledge sharing. J Appl Bus Econ 21(8)

Kodden B, Hupkes L (2019) Organizational environment, personal resources and work engagement as predictors of coaching performance. J Manag Policy Pract 20(3)

Pink D (2009) The surprising truth about what motivates us. Riverhead Books

van Rhenen W (2008) From stress to engagement (Thesis University of Amsterdam). Consulted at http://dare.uva.nl/document/107037

Westman M, Bakker A, Roziner I, Sonnentag S (2011) Crossover of job demands and emotional exhaustion within teams: a longitudinal multilevel study. Anxiety, Stress Coping 24(5):561-577

Wiese L, Rothmann S, Storm K (2003) Coping, stress and burnout in the South African police service in Kwazulu-natal. SA J Industr Psychol

Xanthopoulou D, Bakker AB, Heuven E, Demerouti E, Schaufeli WB (2008a) Working in the sky: a diary study among flight attendants. J Occup Health Psychol 13(4):345-356

Xanthopoulou D, Bakker AB, Demerouti E, Schaufeli WB (2008b) How job and personal resources influence work engagement and financial returns: a diary study in a Greek fast-food company. $\mathrm{J}$ Occup Organ Psychol 82(1):183-200 
Open Access This chapter is licensed under the terms of the Creative Commons Attribution 4.0 International License (http://creativecommons.org/licenses/by/4.0/), which permits use, sharing, adaptation, distribution and reproduction in any medium or format, as long as you give appropriate credit to the original author(s) and the source, provide a link to the Creative Commons license and indicate if changes were made.

The images or other third party material in this chapter are included in the chapter's Creative Commons license, unless indicated otherwise in a credit line to the material. If material is not included in the chapter's Creative Commons license and your intended use is not permitted by statutory regulation or exceeds the permitted use, you will need to obtain permission directly from the copyright holder.

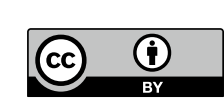

